Int. J. Electrochem. Sci., 15 (2020) 1072 - 1081

\title{
Corrosion Behavior Study of Aluminum Alloy 7075-T6 and 2A12-T6 Joints Prepared Using Friction Stir Welding
}

\author{
Defeng Zhang*, Jun Xia, Qiuguo Yang, Tianhao Wei, Lijie Gong, Siyue She \\ School Of Materials Science and Engineering, Southwest Petroleum University, Chengdu 610500, \\ China \\ *E-mail: 574285778@qq.com
}

doi: $10.20964 / 2020.02 .03$

Received: 12 September 2019 / Accepted: 13 November 2019 / Published: 31 December 2019

\begin{abstract}
The corrosion resistance of FSW welded joints of 6mm-thick dissimilar 2A12 and 7075 aviation aluminum alloy was investigated. It was concluded that the 7075 aluminum alloy was more resistant to intergranular corrosion than 2A12 aluminum alloy, and when the 7075 aluminum alloy was the advancing side (AS) material, the intergranular corrosion resistance of the WNZ of the dissimilar aluminum alloy FSW joint was better than the 2A12 aluminum alloy. But the polarization curve and AC impedance diagram of the electrochemical corrosion test shown that the corrosion resistance of the WNZ of the FSW joint was better than that of the 2A12 aluminum alloy on the advancing side (AS) when the 7075 aluminum alloy was on the advancing side (AS). And when the 7075 aluminum alloy was the advancing side material, the corrosion resistance of each region of the joint was: 2A12BM $>$ HAZ+TMAZ(RS) $>$ WNZ $>7075 B M>H A Z+T M A Z(A S)$.
\end{abstract}

Keywords: FSW; Dissimilar aluminum alloy; Intergranular corrosion; Electrochemical measurement

\section{$\underline{\text { FULL TEXT }}$}

(C) 2020 The Authors. Published by ESG (www.electrochemsci.org). This article is an open access article distributed under the terms and conditions of the Creative Commons Attribution license (http://creativecommons.org/licenses/by/4.0/). 